\title{
Grade 11 students' interconnected use of conceptual knowledge, procedural skills, and strategic competence in algebra: a mixed method study of error analysis
}

\author{
Gunawardena Egodawatte ${ }^{1}$, and Dorian Stoilescu ${ }^{2}$ \\ ${ }^{1}$ University of Toronto \\ 2 University of Western Sydney \\ For correspondence: D.Stoilescu@uws.edu.au
}

\begin{abstract}
The purpose of this mixed-method study was to investigate grade 11 university/college stream mathematics students' difficulties in applying conceptual knowledge, procedural skills, strategic competence, and algebraic thinking in solving routine (instructional) algebraic problems. A standardized algebra test was administered to thirty randomly selected grade 11 students in an urban school in Ontario, Canada. Ten students were later interviewed. In this paper, we discuss the solutions and interviews of five students.

The results showed that the majority of university/college stream mathematics students were in the transition stage from arithmetic to algebra. Another prominent feature of these students' problem solving process was their overuse of procedures without being able to critically evaluate whether these procedures would work or not. They also demonstrated lack of relational, application, and structural abilities when solving instructional problems. We emphasize that, in order to be successful, all components of problem solving (procedural work, local focus, strategic skills, and algebraic reasoning) should work together in a coherent manner, as the main learning challenge in problem solving remains keeping cohesion between its multiple interconnected components. Therefore, it is necessary that to show them the arithmetic-algebraic connection in problem solving and to facilitate them to systematically check their answers in the context of a general strategy.
\end{abstract}

Keywords: problem solving; algebraic thinking; strategic competence; student misconceptions; knowledge types

\section{Introduction}

Research in learning and instruction has given prominent attention to the central role of knowledge. It is generally assumed that the knowledge base of a person is made up of different components (Gagne, Briggs \& Wagner, 1988; de Jong \& Ferguson-Hessler, 1996; Miller \& Hudson, 2007). The most widely discussed components are: conceptual and procedural, apart from other types such as declarative (Gagne et al., 1988; Miller \& Hudson, 2007), strategic (de Jong \& Ferguson-Hessler, 1996), and situational (de Jong \& Ferguson-Hessler, 1996). One of the main arguments within the recent debates on math wars (Klein, 2007; Marshall, 2003; Schoenfeld, 2004) in the US is based on acquiring procedural skills versus teaching for conceptual understanding. Math wars emanate from the discussion in the 1990s in the US on how mathematics should be taught in high schools. As a result, a reform-based curriculum and evaluation standards were introduced instead of the traditional curriculum. The new focus was on teaching mathematics for conceptual understanding rather than teaching for acquiring procedural skills. However, the discussion is still ongoing on among the mathematics education community about the pros and cons of the traditional and new approaches.

Recent Canadian mathematics secondary approaches have been similar. More exactly, the Ontario mathematics curriculum emphasizes the teachers to motivate students to develop their inquiry skills 
in problem solving. In this view, conceptual understanding is considered an essential component in doing mathematics with understanding. In Ontario, grade 11 mathematics students are divided into three streams: university, university/college, and workplace. Students in the university/college stream follow applied mathematics courses in grades 9 and 10. These courses focus on "the essential concepts of the subject, and develop students' knowledge and skills through practical applications and concrete examples" (Ontario Ministry of Education, 2005, p.6). Grade 11 university/college students are aged between 16 and 18 years and intend to pursue mathematics programs that prepare them mainly for technology-related programs at the college level such as finance, business, human services, hospitality and tourism, and health sciences (Ontario Ministry of Education, 2007). These students acquire conceptual and procedural skills from a variety of methods including word problems unlike the university stream students who study more abstract theories and concepts.

The present Ontario secondary school mathematics curriculum argues that both of these groups of students should be given opportunities to solve instructional, routine, and non-routine problems (Ontario Ministry of Education, 2007). Generally, instructional and routine problems are solved by using the techniques learned in the classroom. In contrast, non-routine problems are typically solved by using special techniques such as drawing a diagram, constructing a pattern, or solving a similar problem. Both types of problems improve students' thinking and reasoning abilities (Ontario Ministry of Education, 2007).

Algebra is one of the most abstract strands in mathematics and it has its specific challenges. After widespread promotion by The National Council of Teachers of Mathematics (NCTM), algebra is now a required part of mathematics curricula in the US and Canada (Greens \& Rubenstein, 2008). Australia has also considered algebra as an important part of their high school mathematics curriculum (Australian Curriculum, Assessment and Reporting Authority, 2012). However, many attempts to better prepare students for algebra have not resulted in greater achievement outcomes. Many students are discontinuing from studying higher-level mathematics because of their lack of success in algebra (Achieve, 2008; Pegg, 2010).

Many studies in the past have focused on examining the root causes of students' difficulties in solving algebraic problems (Clement, 1982; Clement, Lochhead, \& Monk, 1981; Kaput \& Clement, 1979). Comparatively, less attention has been devoted to identifying grade 11 university/college stream students' specific difficulties in applying conceptual knowledge, procedural skills, strategic competence, and algebraic thinking. In this study, these students' levels of algebraic thinking were examined when they attempted to solve instructional and routine algebra problems. These problems do not require special solving methods such as solving a similar problem, making a chart or a graph, use of abstraction etc. Therefore, they could be regarded as intermediate problems between transitioning from arithmetic to algebra. According to the Ontario Ministry of Education (2005), by analyzing students' concrete representations of mathematical concepts and listening carefully to their reasoning, teachers can gain useful insights into students' thinking and provide support to enhance their thinking. Based on these views, two research questions were identified for this study. They were: 1. How do students apply conceptual knowledge, procedural skills, and strategic competence to solve routine and instructional algebraic problems? 2. What is the interconnected nature of students' conceptual knowledge, procedural skills, strategic competence, and algebraic thinking? In the next section, we will briefly discuss the available research underlying these research questions.

\section{Conceptual knowledge and procedural skills}

Generally, conceptual knowledge involves an understanding of the meaning of concepts. This knowledge is necessary to understand problems and generate new strategies or adapt known strategies to solve original problems (Hiebert \& Lefevre, 1986). It is a connected web of information in which linking relationships are as important as the pieces of discrete information that are linked 
(Goldman \& Hasselbring, 1997; Groth \& Bergner, 2006; Hiebert \& Carpenter, 1992). The linking process may involve previously learned mathematical concepts that are stored in memory (Bulgren, Lenz, Deshler, \& Schumaker, 1995; Goldman \& Hasselbring, 1997). Skemp (1987) used the term relational understanding, which deals with the knowledge of how to do and why in a problem solving situation. It refers to the ability to deduce specific rules or procedures from more general mathematical relationships (Hiebert \& Carpenter, 1992).

Procedural knowledge nurtures the skills needed for solving problems. Hiebert and Lefevre (1986) described two types of procedural knowledge: a) knowledge of the formal language or system of symbolic representation of mathematical ideas and b) knowledge of the rules or algorithms used to solve mathematical tasks. They argued that procedural knowledge may or may not be learned meaningfully but conceptual knowledge must be learned meaningfully. Procedural knowledge is the ability to follow a set of sequential steps to solve a mathematical task (Bottge, 2001; Carnine, 1997; Goldman \& Hasselbring, 1997; Saenz, 2009). It is a rule-oriented approach to problem solving, which demands knowing how, but not knowing why (Gagne et al., 1988; Hiebert \& Carpenter, 1992). Skemp (1987) used the term instrumental understanding to describe procedural knowledge, which is the knowledge of rules. It involves carrying out a procedure in mathematics without necessarily understanding the reasoning behind those rules.

Although conceptual knowledge and procedural skills can be defined separately, they are interconnected to form a web in problem solving (Kilpatrick, Swafford \& Findell, 2001; Nesher, 1986; Rittle-Johnson \& Koedinger, 2005). However, it is less clear how conceptual knowledge can be elicited and made to work in an integrated fashion with contextual knowledge and procedural skills in problem solving (Saenz, 2009). Although various terms such as mathematical proficiency (Kilpatrick, Swafford \& Findell, 2001), mathematical processes, or mathematical strands (Ontario Ministry of Education, 2005, 2007) are used in mathematics curricula and textbooks, they all imply applying conceptual knowledge, contextual knowledge, and procedural skills in solving problems.

\section{Algebraic thinking and strategic competence}

Algebraic thinking is entirely different from arithmetic thinking. Arithmetical problems are connected, so that reasoning is direct, whereas algebraic problems are disconnected and they require reasoning with unknowns (Booth, 1984). This difference causes serious obstacles for the passage from arithmetic to algebra. Algebraic thinking involves generalization from arithmetic, meaningful use of symbolism, the study of number structure, the study of patterns and functions, and mathematical modeling (Van de Walle \& Folk, 2008). According to Arcavi (1994), symbol sense is the ability to "understand how and when symbols can and should be used to display relationships and generalizations" (p. 31). He further claimed that having a gestalt view of algebraic expressions and equations is a prerequisite for applying basic procedural skills. Bokhove and Drijvers (2010) divided the gestalt view into: a) recognizing patterns (pattern salience), b) recognizing signals and symbols (local salience), and c) strategic decision (what to do next).

As such, algebraic thinking could be considered as the capacity to represent quantitative situations so that relations among variables become apparent (Driscoll, 1999; Kieran, 1996; Swafford \& Langrall, 2000). According to Drijvers, Goddijn, and Kindt (2011), algebraic expertise has a spectrum. First, the basic skills contain procedural work, local focus, and algebraic calculation. Skills such as solving simple equations or simplifying expressions often have a local focus. Symbol sense involves choosing a sensible strategy to interpret the results in a meaningful fashion. Symbol sense in algebra is similar to number sense in arithmetic. Algebraic reasoning is only possible after reasonably mastering the basic operations. Hallagan (2006) and Warren (2003) reiterated this arithmetic-algebraic connection and Drijvers et al., (2011) said that the transition from arithmetic to algebra is difficult for students because the development of symbol sense has given too little explicit attention in current algebra education. 
The competence in selecting a correct strategy to solve a problem is a key factor in solving any mathematical problem. Strategic competence is necessary to determine the direction of problem solving and to understand which stages to follow through in order to reach a solution. A strategy is defined as a logical series of actions, such as: analyzing information, constructing a problem representation, selecting tools for the solution, and planning the various steps to be carried out to reach the solution (de Jong \& Ferguson-Hessler, 1996; Posner \& McLeod, 1982).

\section{Problem solving and metacognition}

An internal part of any mathematical problem solving process is the use of metacognition for monitoring, evaluating, and overseeing the process (Flavell, 1981; Jacobs \& Paris, 1987; Wilson \& Clarke, 2004). Metacognition includes reflection on cognitive activities as well as decisions to modify these activities at any stage of the process solving (Clement, 1982; Mayer, 1982). For Schoenfeld (1985, 1992), metacognitive processes involve knowing the available problem-solving options, evaluating the potential usefulness of these options, and choosing the most efficient route to the goal. Metacognition is involved in choosing and planning what to do, and monitoring what is being done and these behaviors can be exhibited by statements made in the problem solving process (Flavell, 1981). By supporting students to develop metacognitive habits, they can become aware of the impact of rigid associations, inadequate handling of models, inadequate intuitive beliefs, incorrect generalizations and control the overall impact (Fischbein, 1990).

In line with the National Council of Teachers of Mathematics (NCTM) (2000) principles, the Ontario secondary school mathematics curriculum also highlights the importance of metacognition in problem solving. Reflection is a mathematical process, which helps to make conscious decisions and find alternative ways to perform a task (Ontario Ministry of Education, 2005, 2007). Although it is conceptually possible to distinguish the nature of cognitive and metacognitive actions, this distinction is often operationally blurred (Flavell, 1981). Cognition is, of course, implicit in any metacognitive activity and metacognition may or may not be present during a cognitive act and perhaps this presence may not be obvious. Although there are difficulties in distinguishing between cognitive and metacognitive activities in a problem solving situation, metacognition is a necessary act in problem solving.

\section{Students' difficulties in algebra}

There is a rich literature on students' misconceptions and their sources in algebra. A fundamental difficulty for students studying algebra is the use of symbolic language. Wagner and Parker (1999) remarked that the use of two distinct symbol systems (letters and numbers) together in algebra makes possible confusion. They further stated that within the language of algebra, most linguistic difficulties relate to variables and expressions and most translation difficulties arise in translating word problems into equations. According to Sierpinska (2008), students do not have an adequate understanding of variables and they often think that letters are names for concrete objects based on their old knowledge of arithmetic. The use of symbols or letters to represent numbers and expressions is the first difficulty for students. Barrera, Medina and Robayna (2004) categorized algebraic errors into three sources: algebraic errors originating in arithmetic, use of formulas or procedural rules inadequately (procedural errors), and errors due to the properties themselves of algebraic language (structural errors).

Often, intuitive knowledge manipulates and hinders the formal interpretation or the use of algorithmic procedures (Fischbein, 1994; Fischbein \& Barash, 1993). For example, students' misinterpretation of $(a+b)^{5}$ as $a^{5}+b^{5}$ or $3(a+b)^{2}$ as $3 a^{2}+3 b^{2}$ could be regarded as evolving 
from the intuitive application of the distributive law. Contrary to this view, there are other opinions from other researchers. Matz $(1980,1982)$ observed the sources of above errors as the use of a known rule in a new situation where it is inappropriate. Kirshner (1985) observed the source of the same error as the overgeneralization of rules. Radatz (1979) viewed this as the application of irrelevant rules or strategies.

Operating with negative integers and over-generalization of cancelling procedures have their roots in arithmetic misconceptions (Norton \& Irvin, 2007; Stacey \& Chick, 2004; Stacey \& MacGregor, 1999; $\mathrm{Wu}, 2001)$. This is partly because of the failure of transferring arithmetic understanding to algebraic contexts (Norton \& Irvin, 2007; Stacey \& Chick, 2004; Stacey \& MacGregor, 1999). Many algebraic problems are difficult for students, because solving them may require an understanding of the conceptual aspects of fractions, decimals, negative numbers, equivalence, ratios, percentages, or rates (Norton \& Irvin, 2007; Stacey \& Chick, 2004; Stacey \& Macgregor, 1999). According to Lee and Wheeler (1989), the worlds of algebra and arithmetic have no connections at least in the secondary school teaching practices. There are many covert signs that secondary school algebra has its own rules, which are not necessarily deducible from arithmetic (Wheeler, 1989). The consequence is that these covert signs leave many students unsure of the grounds that justify particular algebraic transformations. Therefore, transitioning from arithmetic to algebra is not an easy process for some students. Based on the above discussion, our paper will focus on the interconnected nature of conceptual knowledge, procedural skills, algebraic thinking, and metacognitive actions within the domain of strategic competence.

\section{Methodology}

This paper was based on a study conducted in grade 11 university/college stream mathematics classrooms in four Ontario public schools to identify students' misconceptions and thinking patterns in solving algebraic problems (Author 1, 2011). The mixed method research design was sequential exploratory (Clark \& Creswell, 2008), in that, the collection and analysis of quantitative data was followed by the collection and analysis of qualitative data.

The first phase of the study involved the standardization of the test instrument. In the first phase, a test instrument with 26 routine (instructional) algebraic problems was administered to 30 randomly selected grade 11 university/college mathematics students in an urban secondary school in Ontario. All the test items were based on the Ontario grade 9 and grade 10 mathematics curriculum (Ontario Ministry of Education, 2005). The test items were under four conceptual areas: variables, expressions, equations, and word problems. After the first trial, items with a facility value between 0.3 and 0.8 were selected for a second trial with another 30 students in the same stream in another school. The reliability coefficient for the test using the Spearman-Brown prophecy formula (Gay, Mills \& Airasian, 2006) was 0.8 . Four items with low/high facility values were omitted and a second trial was conducted with another 30 students in the same stream in a different school. The reliability coefficient for the second trial was 0.88 . Three items were omitted based on the same criteria and the final test contained 19 items. All these schools were public secondary schools having all the three streams of mathematics starting from grade 9. The schools follow the Ontario secondary mathematics curriculum. The students were aged 16 and 17 and were born in Canada or migrated to Canada at an early age. All of these sample students had followed the curriculum and textbooks for the university/college mathematics stream from grade 9 .

The final test was administered to 30 randomly selected grade 11 students in the same stream in another school. These students were from eight different grade 11 classes taught by four different teachers. After marking the test, students' incorrect responses for each problem were grouped with their percentages. Later, ten students were randomly selected to interview from the three conceptual areas that recorded the highest mean percentage of incorrect responses. These students represented 
the highest incorrect response category in each of the three conceptual areas. Although we did not interview students from the 'no response' category, it is possible that some of these students may have had the same or similar difficulties as other students. It is possible to have a small number of students in this category who were not able to attempt the item due to psychological reasons such as forgetfulness, low enthusiasm, test anxiety etc. In the interviews, students were asked to work out the problem again while explaining their thinking using a think-aloud procedure (De Jong, 1987; Ericsson \& Simon, 1993). Prompts such as "explain more", "go ahead" were given and "how" and/or "why" type of questions were asked whenever necessary. Corrective feedback was not provided during the process. Each interview lasted between 20 and 30 minutes. The interviews were tape-recorded and later transcribed.

The interview transcripts in conjunction with students' written work were used for the analysis. Interview transcripts were considered as episodes. Student reasoning patterns were discovered with the help of semantic features in the script, such as ideas, argument chains, use of examples, or impasses. Through simultaneous analysis and discussion with subject experts, we conjectured about students' application of conceptual understanding and procedural skills, selection of strategies and their level of algebraic thinking. Metacognition was considered as a part of the strategy.

Below, we discuss five different student interviews. Based on our preliminary analysis, word problems were the most difficult area for students followed by expressions, equations, and variables. In this paper, we will discuss the interviews for two word problems, two algebraic expressions, and one equation based on the ratio of the mean error responses for each conceptual area. The interviewed students in each category belonged to the most common incorrect response in the test. Some students used different methods in the interview than the test to work out the same problem and came up with different answers. The problems under variables reported the lowest mean error percentage and we, therefore, did not consider interviewing students in this area. Another reason for this decision was that the concept of variable was omnipresent in the test items of the other three conceptual areas.

\section{Results}

Our initial quantitative analysis of the test answers showed that students have mainly resorted to use procedures with a low level of proper conceptual understanding. The mean error percentages for each conceptual area were: word problems (85\%), expressions (79\%), equations $(48 \%)$, and variables $(37 \%)$. Based on the ratio of these percentages and the most common error type, we selected five answer types to discuss below.

\section{Problem 1}

This problem under algebraic expressions demands at least two procedural skills -- factorize and simplify the terms.

$$
\text { Simplify: } \frac{x a+x b}{x+x d}
$$

There were $13.3 \%$ correct answers, $43.2 \%$ incorrect answers, and $43.3 \%$ with no response. The most common incorrect answer was $\frac{a+b}{d}(66.7 \%)$ out of the $43.2 \%$ of incorrect answers. The other incorrect response categories were $\frac{x^{2} a b}{x^{2} d}, \frac{x^{2} a b}{x^{2} d}=\frac{a b}{d}, 2 x^{2} a b d, \frac{x a b}{x d}$, and $\frac{2 x a b}{2 x d}$, which comprised $33.3 \%$ of the incorrect answers. The above answers indicate to the arbitrary manipulation of symbols to produce a single answer. These students have not shown any apparent conceptual understanding other than using irrelevant procedures. 
We interviewed Rita for her answer, $\frac{a+b}{d}$.

R - Rita I I Interviewer

I - Can you please explain your answer?

$\mathrm{R}-\mathrm{So}, x a+x b$ over $x+x d$. You multiply by this, right? (pointing to $x a$ ). So I divided this, because there's an $x$ over, and divided by another $x$. So this cancels off with this one $\left(\frac{x a+x b}{x+x d}\right.$ ) and I got this one also off with this one $\left(\frac{x a+\chi b}{x+\chi d}\right)$. So, there are really no $x$ 's anymore. So I'll write $a+b$ over $d$.

I - (pointing to the first cancelled $x$ in the denominator) Is there anything remaining here after you cancelled out the $X$ 's?

$\mathrm{R}-\mathrm{No}$, nothing.

By looking at Rita's method, we can see that she was able to identify the required operation to solve the problem, which was separating out the common factor $x$. This shows that she was able to identify the correct strategy to solve the problem. However, she followed a conceptually incorrect procedure by separating the rational expression into two terms. This error occurred while she was carrying out the strategy and the error was procedural. We believe that she focused her attention on the isolated terms in the expression rather than the expression as a whole while not paying attention to the relational nature of the terms. This shows a lack of understanding of the interconnected nature of individual terms inside a rational expression. Based on this incorrect separation, the rest of her answer was technically correct, since $\frac{x a}{x}=a$. When writing the final answer, she had missed to use an important structural property in algebra $\left(\frac{x}{x}=1\right)$. The last two lines of the interview bear some evidence that either she did not use or forgot to use this structural property.

There is no indication that Rita attempted to use metacognition in her problem solving. We think that a better place to think holistically for her would be to compare her final answer with the initial problem and check the validity of the answer. We prompted her to do this by asking a question in the end of the interview. Perhaps, some deep thinking of the possibility of the answer would have led her to correct her answer. In sum, Rita's errors were basically related to her misunderstanding of the relational nature of terms, lack of understanding of structural properties, and incorrect application of rules and procedures. To a certain extent, using metacognition would have been helpful for her at least to understand her mistakes. Rita's thinking was linear and unidirectional. Instead, she should have used circular thinking to reflect on the answer and check back its consistency with the problem. It was possible that this reflection would have opened new insights into the problem.

\section{Problem 2}

The second problem was simplifying an algebraic expression. By simplifying, we meant to eliminate the parenthesis. We wanted to examine how students multiply two algebraic fractions when there is no visible denominator in the first fraction and the second fraction was inside parentheses.

Simplify: $x\left(\frac{a}{b}\right)$

There were $67.2 \%$ incorrect answers, $23 \%$ correct answers, and the rest were in the 'no answer' category. In the incorrect category, $36.7 \%$ were incorrect answers such as $x(a \times b), x(a b)$, 
$(x a)(x b)$, or other similar types. Another $19.2 \%$ of the incorrect responses were $\frac{a x}{b x}$. Joshua had this solution and we decided to interview him for his insights. However, he changed his strategy completely in the interview.

Joshua's work: $x\left(\frac{a}{\not b}\right) \times b=x(a \times b)=x(a b)=(x a)(x b)=x^{2}+x b+a x+a b$.

$\mathrm{J}$ - Joshua $\quad$ I - Interviewer

I - Can you please explain your answer?

$\mathrm{J}$ - You divide....... mean you multiply $b$ besides $a$. So the denominators get cancelled out. So it is just equal to $x\left(\frac{a}{\not b}\right) \times b$ which is equal to $x(a b)$.

I - Can you explain it again?

J - You just....because you want to.... like.... cancel out. So to make it easier you just multiply....you divide.......you multiply this numerator. So this is cancelled and it gets simplified and you get....

I - How did you get $(a \times b)$ ?

J - Em...when you multiply...no, wait. You multiply these two together which will be like that and then you put them in here and then you get $x$ times $a$, which is $x a$ and $x$ times $b$, which is $x b$. [He wrote $(x a)(x b)]$

$\mathrm{I}-$ Is there any sign in between $x a$ and $x b$ ?

$\mathrm{J}$ - Well, it is the multiplication sign there in between the brackets, yeah. I think that's how you do it. And then if you want to simplify, I think you do....so there are two binomials and so you multiply this first value into the second (drawing arrows from the first $x$ onto both $x$ and $b$ ) and then you multiply this into the next (drawing arrows from $a$ onto both $x$ and $b$ ). So it would be $x^{2}+x b+a x+a b$.

I -How did you get the plus signs?

I - Because you're simplifying it. So even though it is multiplied in here, you just add. Yeah, that's it.

Joshua's overall solution method shows a chain of unconnected procedures. He demonstrated a number of conceptual errors. Selecting an incorrect strategy to solve the problem led to a series of procedural errors. Joshua's reasoning for his actions clearly indicates that he has manipulated the letters not according to accepted procedural rules or with correct conceptual understanding. His errors started by eliminating the denominator of the second fraction. Finally, Joshua ended up with an expanded and more complicated answer than the problem itself. He showed no clear objective when expanding/simplifying the expression.

Apart from committing a number of procedural errors, Joshua had a poor understanding of some structural properties in algebra such as $\frac{b}{b}=1(b \neq 0)$ and identifying a binomial. Using a series of equal signs to equate different algebraic expressions shows his inadequate understanding of the relational aspect of the equal sign. Joshua seemed to have perceived some misleading visual similarities between the two algebraic entities $x a$ and $(x+a)$ when he said that the former is a binomial. He demonstrated poor relational understanding of algebraic expressions to one another.

Further to poor understanding of structural features of algebra and relational understanding, Joshua's lack of ability to apply correct procedures was obvious from his solution. As in the previous 
case of Rita, Joshua's thinking was also linear and directional. There is no indication that he reflected on the process or paused back to check the correctness of the solution.

\section{Problem 3}

This is a problem in solving a system of linear equations. We did not ask the students to solve the equations. Instead, we requested them to explain the process verbally. This problem is different from previous ones as we did not expect the students to follow procedures. Instead, we tested their conceptual understanding of the procedures.

Consider solving the linear system: $a+b=5, a-b=7$

a) To eliminate $a$ from both equations, do you add or subtract the two equations?

b) To eliminate $b$ from both equations, do you add or subtract the two equations?

c) Will you obtain the same solution if you add or subtract the two equations? Explain.

Since the problem has three parts, we give here the percentages for the last part. There were $14 \%$ correct answers, $43 \%$ incorrect answers, and another $43 \%$ with no answers. The most common incorrect answer in part (a) was add and in part (b), it was subtract. Other forms of incorrect answers were: subtract from the first equation and add to the next equation; depends on the equation; and add to the first equation and subtract from the next equation. We noticed that, in a large number of incorrect answers, students had tried to consider only one equation at a time to answer the question rather than considering the system of equations together. We randomly selected Colin from the highest incorrect response category.

C-Colin I - Interviewer

I - How do you answer part (a).

C - You would subtract $a$.

I - Why?

C - I don't know. I think because it is positive here (pointing to $a$ in the first equation), you subtract it from there.....and from this one (pointing to $b$ in the second equation), you would have to add instead of subtracting to make it equal to zero.

I - So, what is the answer for part (a)?

C - I think you would have to do both.

I - What is the answer for part (b)?

C - You do the same. You would add and subtract. For this one (pointing to $b$ in the first equation), you would subtract and for this one (pointing to $b$ in the second equation), you would add.

I - Can you explain more?

$C$ - For this $b$ (pointing to $b$ in the first equation), since you have to eliminate it, you would have to subtract it in order to equal to zero and for this one (pointing to $b$ in the second equation), you would have to add.

I - What is the answer for part (c)?

C - You would not obtain the same solution.

I - Can you explain?

$\mathrm{C}$ - Because the sum of it is different. Five is not equal to seven. In this (pointing to the first equation) $a$ and $b$ have a different value than this (pointing to the second equation). So, that's why the sum is different.

I - Do you have a way to verify your answer?

C - Like in a math way?

I - Whatever the way you like.

C - You can just tell because the sum of it... 5 is just not equal to $7 \ldots$ you can just tell from that. That's why you can't get the same solution. Because $a$ and $b$ in this case (pointing to the first equation) have a different value than $a$ and $b$ in this case (pointing to the second equation). 
I - Can you show me how to solve this linear system of equations?

C - (He wrote up to the step: $a+b-5=a-b-7$ and said that he does not know how to proceed further).

I - What do you mean by solving these two equations?

C - It is called substitution... it is for linear equations.

I - When you are asked to solve the equations, what are you going to find out?

C-You have to find $x$ and $y$.

I - In this problem?

$C-a$ and $b$.

We can infer that Colin explained the solution of equations by hypothesizing the elimination method. However, his focus was on only one equation at a time and operated directly on the variables to remove them. Further, he was confused about many rules of the elimination method. He tried to use the substitution method in an unconventional manner substituting for zero in both equations $(a+b-5=a-b-7)$. This method would work for particular systems of equations such as the given one but it would not work for others. When he was asked to solve the equations, using the elimination or any other method, he could not proceed. He did not demonstrate any knowledge of the elimination method although he mentioned the word eliminate in the interview.

As a whole, Colin did not have the correct conceptual model to apply and solve the two equations using either elimination or substitution. Only a partial understanding of the principles of substitution and elimination led him to arrive at incoherent or faulty conclusions. Overall, Colin knew some structural features of algebra (numbers) such as equating the same amounts $(a+b-5=a-b-7)$, stating that negative and positive signs cancels out (although he did not mention that the amounts should be equal), and explaining the relationship between the two sides of an equation. His lack of relational reasoning may have prevented him from selecting a correct strategy.

We think that Colin had problems with grasping the relationship between the two equations in order to formulate a correct strategy. This may have been caused by not understanding the structure of the linear system of equations. This is evidenced by his attempt to obtain the answer by focusing on only one equation. Although he mentioned the word substitution, he was not able to select a correct strategy to solve the problem. We prompted him to reflect on his answer by asking the question "Do you have a way to verify your answer?" His answers do not indicate that he used metacognitive actions in the process.

\section{Problem 4}

This word problem is an instructional problem based on a day-to-day experience. Students need to identify the relationships among different quantities to solve the problem.

Mr. Robertson shared his stamp collection with his two sons and the daughter: Javier, Raul and Teresa. Teresa received 5 times more the number of stamps than Javier did, and 4 less stamps than those received by Raul. The whole quantity received by Javier and Raul was 22 stamps. How many stamps did Mr. Robertson give to each child?

There were $20.3 \%$ correct answers, $63.4 \%$ incorrect answers, and the rest were in the unanswered category. In the incorrect category, $20 \%$ of the students used arithmetic methods, while another $16 \%$ used algebraic methods. The students who used an algebraic method mainly failed to identify a correct strategy to solve the problem. The students who were unable to form equations with the given relationships resorted to estimate answers by guessing or working backwards to reach unrealistic solutions. We categorized Emy's answer as algebraic as she has attempted to use letters for variables. She has the following answer in the test, but she used a completely algebraic approach and elaborated 
her algebraic thinking in the interview. This answer shows a mix of algebraic, arithmetic, trial and error and guessing approaches.

22 stamps for $\mathrm{J} \& \mathrm{R}$

-4 from $22=18$ stamps for $\mathrm{T}$

$\mathrm{T} \div 5=3.6 ; \therefore 3$ stamps for Javier.

$3-22=19=R^{\prime}$ s stamps

$19-4=$ Teresa's $=15 ; 15 \div 5=3$

15 stamps for Teresa

3 for Javier

19 for Raul

Emy articulated a different thinking pattern in a lengthy interview.

E - Emy I - Interviewer

E - I know that Teresa received 5 times...so I represented the number of stamps with $x$.

$\mathrm{I}-\mathrm{Ok}$, what is $X$ ?

$\mathrm{E}$ - It is the number of stamps Teresa received. And 5 is the number...as she received 5 times more than Javier and Javier received 4 less than Raul. So I think Teresa's number is $5 x$. Raul has $-4 x$.

I - Why?

E - Javier has $-4 x$ because he received 4 less than Raul. Then, I do not know how much Raul received, so I am going to do $4 x-x=22$.

I - How did you get that equation?

E - Because Raul received 4 less than Javier and those two numbers are 22. That's how I am going to do $4 x-x=22$. (Solves the equation as $\frac{-5 x}{-5}=\frac{22}{5} ; x=\frac{22}{5} ; x=4.4$ ). This is the number of Raul's...the number of Javier's stamps (pointing to $x=4.4$ ). Javier received 4.4 stamps. Then to calculate Teresa's stamps, I am going to do Teresa minus Javier's stamps... that is $4 \ldots$ so I am going to do $5 x-4=22$. (Solves the equation as $5 x=22+4 ; \frac{5 x}{5}=\frac{26}{5}$; $x=5.2$ ) This is the number of Teresa's stamps (pointing to $x=5.2$ ).

I - Both times, you had the same $x$ with two different values. Can you explain?

E - In my view, it is right because I used $x$ to represent the number of ...to represent the stamps....that's why.

I - Stamps of whom?

E - All of them.... like every stamp in the question.

I - Is it the total number of stamps?

E-Yes.

I - Do you think that it is possible to get decimal numbers for the number of stamps?

E - No, because stamps cannot be divided into parts.

I - Can you explain to me your difficulties when you were formulating these equations?

E - Yeah....like.... the total number of stamps is not given and this 5 times (pointing to the question) and 4 less confuses me sometimes. I know that 5 times is going to be another number and 4 less is going to be another one. But I do not know how.

Emy's main difficulty was translating the word problem into algebraic language and selecting a correct strategy to solve the problem. Her initial difficulty was to select a starting variable. Her explanations were haphazard and incoherent. She constantly tried to obtain answers in almost every step of the solution (both in the test and the interview) rather than attempting to understand the connected nature of the variables. This shows lack of understanding of the relational aspects of the problem and its steps to one another. 
Emy's limited conceptual understanding has prevented her from ascribing meaning to the symbols. For example, she constantly hesitated over symbolizing the correct algebraic quantity for each person (hesitating over whether $x+4$ or $x-4 ; 4 x$ or $-4 x$ ). She also used the same variable for the number of stamps for different people (or used the same total for every relationship). Overall, she had a poor symbol sense because all of her attempts to symbolize the given relationships were failed. Her explanations were always ambiguous and she was not even concerned with the decimal number of stamps in her answer.

We conclude that Emy's approach is procedural. In almost every step, she attempted to obtain an answer. In addition, she did not show a coherent strategy to solve the problem. While solving the problem, the student often made poor strategic decisions with constant hesitation. Apart from that, it was difficult for her to realize the mistakes as she did not check back for the correctness of her answers.

\section{Problem 5}

In this word problem, students were asked to build up an algebraic expression. This problem is different from others as there was no visible procedural work to be carried out. Students need to have a correct conceptual understanding of variables and patterns to solve the problem.

There are $n$ girl scouts in a parade. There are 8 girls in each row. Write an algebraic expression to find out how many rows of girl scouts are marching in the parade.

There were $20 \%$ correct answers and $10 \%$ no responses. Seventy percent of the students had struggled with identifying a correct strategy. Out of the $70 \%, 20 \%$ of the incorrect answers were $8 n$.

We observed a number of other incorrect responses such as $n^{8}, n=\frac{8}{r}, 8 n+n, 8$, and $8 \times n=0$, and so on.

The most common incorrect answer was $8 n$ and we interviewed Andrea in this category. She showed lack of confidence at the beginning of the interview. However, she managed to get the correct answer later by establishing an arithmetic-algebraic connection.

$$
\text { A - Andrea I - Interviewer }
$$

I - Can you explain your answer please?

A - So...yeah... $n$ girls.... ${ }_{n}$ is not given..... and since there are 8 girls in every row....n is a variable....and since there are 8 girls in every row... (long pause, no answer. Later drew 8 small circles in a single column)

I - What are these? (pointing to the circles)

A - They are rows.

I - How many rows?

A - Eight.

I - What does that mean?

A - There are 8 girls in each row and depending on how much rows are..... there will be 8 girls in each row.

I - So, where's $n$ here? (pointing to the diagram)

A - I don't know. It's a variable. It can be anything.

I - Okay...then, what's the answer?

A - 8n.

I - How did you get it?

A - Oh... hold on.... $\frac{n}{8}$. 
I - Why?

A - Because, say, if it is like 64 girls.... 64 divided by 8 equals how many rows.

Andrea used three different strategies to solve the problem. First, she tried to use intuition. Then she tried to draw a diagram to solve the problem and finally she was able to establish a connection between arithmetic and algebra. At one stage, Andrea claimed that 8 is the multiplier ( 8 rows), and later she claimed that 8 is the multiplicand ( 8 girls in each row). When she failed to solve the problem intuitively, she tried to concretize it by drawing a diagram.

Normally, it is difficult for a student to draw a diagram in this problem, since the total number of girl scouts is a variable. Andrea correctly identified that $n$ cannot be represented accurately in a diagram. During her two failed attempts, she demonstrated some poor representational skills. Confusing with the multiplier and multiplicand is a sign of not properly understanding the structure of the problem. Overall, Andrea's strategic thinking was fine as she tried three different strategies and finally she was able to emulate the knowledge from the numerical example to solve the algebraic problem and vice versa. In other words, her ability to move back and forth from the specific to the general and the general to the specific was an indication of her developed algebraic thinking and the understanding of the structure of the problem.

It is important to note that unlike other students, Andrea was able to pick up a correct arithmetic example to guide her without any clue from the interviewer. This shows that her relational understanding of the various forms of the problem was fine. We also can evidence that she has used metacognition during the interview. After giving the wrong answer $8 n$ at the end, she paused to think for a while and suddenly came up with the correct answer using a similar arithmetic problem showing some signs of reflection there.

\section{Conclusion and Discussion}

In our analysis, we attempted to identify the interconnected nature of conceptual knowledge and procedural skills and students' level of algebraic thinking. The initial difficulty for students who failed to solve the problems correctly was their inability to select a correct strategy. Their approach to problem solving was mainly procedural rather than conceptual. They were eager to apply hasty procedures before identifying a correct strategy. Choosing an incorrect strategy often led to applying wrong procedures and demonstration of poor conceptual understanding. Another visible feature was their lack of use of metacognition during the solving process. This has led some of them not to understand their mistakes during the process and in the final answer.

We presented problem 1 and problem 2 in context-free situations. These two problems mainly demanded procedural skills. Both Rita and Joshua showed lack of understanding of applying procedures in context-free situations. It was sometimes difficult for us to find out whether students carried out procedures with correct conceptual understanding. For example, we were not convinced whether Rita cancelled out the common term $x$ in problem 1 with un understanding of the underlying structural property of the cancellation, which is $\frac{x}{x}=1$. Problems 3,4 , and 5 demanded more conceptual understanding. It is highly unlikely that we could decide whether the students had correct conceptual understanding of all the required properties, rules, or theories related to the given problems. For example, we would not be able to assess students' understanding of the axioms and properties in algebra that are used in solving algebraic equations. We think that the interplay among various knowledge components, skills, and strategies used to solve the problem is more important. 
Our study showed that students who failed to select a correct strategy often failed to demonstrate proper algebraic thinking in the solving process. In order to be able to select a correct strategy, students need to have an overall view of the problem, not just to have a focus on some isolated parts of it. Both Emy and Colin failed to find a correct strategy because their focus was on isolated elements of the problems. Word problems were difficult for students because these problems involved converting the given relationships into algebraic forms (translation). This is one of the intellectual challenges for students. An algebraic simplification such as the one in problem 2 does not need this translation but it involves a translation from one algebraic form to another.

All the students in this study except Andrea had a narrow focus on the problem. They often carried out procedures without demonstrating proper conceptual understanding. They did not demonstrate operating control mechanisms during the solving process since they were not aware of their mistakes. This is a great indication that these students did not consistently use metacognition in their problem solving practices.

One of the main findings of our study was that these students need to be given concrete examples rather than abstract situations. Andrea's work is an example of trying to concretize the situation with numbers. In that sense, we believe that these students particularly need to see the algebraic-arithmetic connection in their problems even though they had already passed that stage. They usually were confused with purely symbolic or algebraic forms. As our sample of students was from four different teachers, we do not think that the student behaviors occurred due to the teaching method. All of these students had similar difficulties in using symbols. From the results of our analysis, we only can say that these students try (or like) to think in terms of concrete situations. We only can infer the reasons for this behavior and more research is necessary to find the real causes.

Our next finding was that these students were weak in three areas in algebraic problem solving. First, they lack application skills such as strategic skills, procedural skills, and metacognitive skills. Second, they lack proper relational skills such as translation of one form to another, usage of the equal sign etc. Third, they did not show a proper understanding of the structural features of algebra such as properties, axioms, and other required conceptual features. It is important to note that these three areas are not mutually exclusive. For example, relational understanding is, in a way, related to structural features of algebra. A specific example would be the knowledge of the equal sign, which is both relational and structural. An interconnection exists among three areas in a deeper sense. We conclude that both conceptual understanding and procedural skills should be applied in varying degrees when performing tasks in each of the above three areas. To demonstrate proper relational and structural skills, students need to have more conceptual understanding while application skills need to have more procedural knowledge.

Many research studies in the past on students' difficulties in algebra were conducted for younger groups of students targeting the transition from arithmetic to algebra (Cai \& Knuth, 2014; Pycior, 1984; Usiskin, 1988; Wheeler, 1989; Wu, 2001). Some of these studies have used non-routine, algebraic word problems. According to Carraher and Earnest (2006), systematic teaching experiments and research is necessary to know the ramifications of algebra-fied arithmetic. The point of departure in our study was that our problems were routine classroom exercises and our results were based on an older group of students. These results were not well documented in the past and we attempted to do that. We selected students who made errors for the interviews. Therefore, out findings are relevant to the students in grade 11 university/college stream who have difficulties in solving instructional algebraic problems. These findings should not be generalized to the whole grade 11 mathematics student population. 
Usually, grade 11 university/college stream students intend to pursue carriers in finance, business, human services, health sciences and so on. Unlike university stream students who intend to follow academic paths, university/college stream students used to think in terms of concrete situations. This is because of the applied nature of problems that they encounter in their studies and future carriers. In our view, they need more verbal skills, communication skills, and the ability to read, understand, and translate information accurately. They need these skills more than the university stream students who often face abstract problems. The results of our study indicated that these skills should be improved in them by using concrete word problems and showing them the arithmetic-algebraic connection. In this way, they will learn with understanding. This approach is again helpful as most of these students were in the basic stage of applying algebraic concepts and they lacked the symbol sense to represent problems algebraically. Teachers should provide them with problems that are suitable for their level of abstraction. Before selecting a strategy, they must be taught to have an overall view of the problem and not to focus much attention on the individual parts of the problem. This would allow them to start the algebraic solution with a correct choice of the starting variables without following incorrect minimal routes (Nesher, Hershkovitz \& Novotna, 2003).

Last but not least, students should be trained to develop metacognition strategies in order to evaluate the reasonableness of their choices. When these techniques are not available to them, they resort to uneducated guessing and trial-and-error methods (Emy's work). We conclude that teacher professional development sessions are excellent venues to discuss these findings and our results would also be important to researchers and curriculum developers in mathematics education in any context.

\section{References}

Achieve (2008). Mathematics at work: The building blocks of success. Retrieved 15 March, 2014, from http://www.achieve.org/files/BuildingBlocksofSuccess.pdf

Arcavi, A. (1994). Symbol sense: Informal sense-making in formal mathematic. For the

Learning of Mathematics, 14(3), 24-35.

Australian Curriculum, Assessment and Reporting Authority [ACARA] (2013). Mathematics Australian Curriculum: Rational. Retrieved 15 March, 2014, from http://www.australiancurriculum.edu.au/Mathematics/Rationale

Barrera, R. R., Medina, M. P., \& Robayna, M. C. (2004). Cognitive abilities and errors of students in secondary school in algebraic language processes. In D. E. McDougall \& J. A. Ross (Eds.), Proceedings of the Twenty-sixth Annual Meeting of the North American Chapter of the International Group for the Psychology of Mathematics Education, Vol. 1, (pp. 253-260). Ontario Institute for studies in Education, University of Toronto, Canada.

Bokhove, C. \& Drijvers, P. (2010). Symbol sense behavior in digital activities. For the Learning of Mathematics, 30(3), 43-49.

Booth, L. R. (1984). Algebra: Children's strategies and errors. Windsor: NEFR-Nelson.

Bottge, B. (2001). Reconceptualizing mathematics problem solving for low-achieving students. Remedial and Special Education, 22(2), 102-112.

Bulgren, J. A., Lenz, B. K., Deshler, D. D., \& Schumaker, J. B. (1995). The content enhancement series: The concept comparison routine. Lawrence, KS: Edge Enterprises.

Cai, J. \& Knuth, E. (2014). Early algebraization: A global dialogue from multiple perspectives. Springer.

Carnine, D. (1997). Instructional design in mathematics for students with learning disabilities. Journal of Learning Disabilities, 30(2), 130-141.

Carraher, D. W. \& Earnest, D. (2006). Journal for research in mathematics education, 37(2), 87-115.

Clark, V. L. P., \& Creswell, J. W. (Eds.). (2008). The mixed methods reader. Thousand Oaks, CA: Sage.

Clement, J. (1982). Algebra word problem solutions: Thought processes underlying a common misconception. Journal for Research in Mathematics Education, 13(1), 16-30.

Clement, J., Lochhead, J., \& Monk, G. (1981). Translation difficulties in learning mathematics. The American Mathematical Monthly, 88(4), 286-290.

De Jong, F. (1987). Differences in the self-regulation processes between successful and less successful students and the prediction of learning performances in case of comprehension and learning of text. In P. R. J. Simons \& G. Beukhof (Eds.), Regulation of learning (pp. 33-45). Den Haag: SVO-Selecta.

de Jong, T. \& Ferguson-Hessler, M. G. M. (1996). Types and qualities of knowledge. Educational Psychologist, 31(2), 105-113.

Driscoll, M. (1999). Fostering Algebraic Thinking: A Guide for Teachers Grades 6-10. Portsmouth: Heinemann.

Drijvers, P. Goddijn, A. \& Kindt, M. (2011). Algebra education: Exploring topics and themes. In P. Drijvers (Ed.), Secondary algebra education: Revising topics and themes and exploring the unknown (pp. 5-26), New York: Sense Publishers. 
Egodawatte, G. (2011). Secondary school students' misconceptions in algebra, Unpublished Ph. D. Thesis, University of Toronto, Canada, http://hd1.handle.net/1807/29712.

Ericsson, K. A., \& Simon, H. A. (1993). Protocol analysis: Verbal reports as data. Cambridge: MIT.

Fischbein, E. (1990). Introduction. In P. Nesher \& J. Kilpatrick (Eds.), Mathematics and cognition (pp. 1-13). Cambridge University Press.

Fischbein, E. (1994). The interaction between the formal, the algorithmic, and the intuitive components in a mathematical activity. In R. Biehler, R. W. Scholz, R. Straber, \& B. Winkelmann (Eds.), Didactics of mathematics as a scientific discipline (pp.231-245). Dordrecht:Kluwer.

Fischbein, E. \& Barash, A. (1993). Algorithmic models and their misuse in solving algebraic problems. Proceedings of the Seventeenth Annual Conference of the International Group for the Psychology of Mathematics Education, 1 (pp. 162-172). Tsukuba, Japan.

Flavell, J. H. (1981). Cognitive monitoring. In W. P. Dickson (Ed.), Children's oral communication skills (pp. 35-60). New York: Academic.

Gagne, R. M., Briggs, L. J., \& Wagner, W. W. (1988). Principles of instructional design, NY: Holt, Rinehart and Winston.

Gay, L. R., Mills, G. E. \& Airasian, P. (2006). Educational research: Competencies for analysis and applications, (Eighth edition). NJ: Pearson Education Inc.

Goldman, S. \& Hasselbring, T. S. (1997). Achieving meaningful mathematics literacy for students with learning disabilities. Journal of Learning Disabilities, 30(2), 198-208.

Greens, C. E. \& Rubenstein, R. (2008). Algebra and algebraic thinking in school mathematics, Seventieth yearbook, NCTM.

Groth, R. E. \& Bergner, J. A. (2006). Preservice elementary teachers' conceptual and procedural knowledge of mean, median and mode. Mathematical Thinking and Learning, 8(1), 37-63.

Hallagan, J. E. (2006). The case of Bruce: A teacher's model of his students' algebraic thinking about equivalent expressions. Mathematics Education Research Journal, 18(1), 103-123.

Hiebert, J. \& Carpenter, T. (1992). Learning and teaching with understanding. In D. Grouws (Ed.), Handbook of Research on Mathematics Teaching and Learning (pp. 65-97), NY: Macmillan Publishing Company.

Hiebert, J. \& Lefevre, P. (1986). Conceptual and procedural knowledge in mathematics: An introductory analysis. In J. Hiebert (Ed.), Conceptual and procedural knowledge: the case of mathematics (pp. 1-28). Hillsdale, NJ: Erlbaum.

Jacobs, J., \& Paris, S. (1987). Children's metacognition about reading: Issues in definition, measurement, and instruction. Educational Psychologist, 22, 255-278.

Kaput, J. \& Clement, J. (1979). Letter to the editor. Journal of Children's Mathematics Behavior, 2(2), p. 208.

Kieran, C. (1996). The Changing Face of School Algebra. Invited Lecture for ICME-8 Congress in Spain.

Kilpatrick, J. E., Swafford, J. E., \& Findell, B. E. (2001). Adding it up: Helping children learn mathematics. Washington, DC: National Academy Press.

Kirshner, D. (1985). Linguistic and mathematical competence. For the Learning of Mathematics 5 (2), 31-33.

Klein, D. (2007). A quarter century of US 'math wars' and political partisanship. Journal of the British society for the history of mathematics, 22(1), 22-33.

Lee, L., \& Wheeler, D. (1989). The arithmetic connection. Educational Studies in Mathematics, 20, 41-54.

Marshall, J. (2003). Math wars: Taking sides. The Phi Delta Kappan, 85(3), 193-200.

Matz, M. (1980). Towards a computational theory of algebraic competence. Journal of Mathematical Behavior, 3(1), 93-166.

Matz, M. (1982). Towards a process model for school algebra error. In D. Sleeman and J. S. Brown (Eds.), Intelligent tutoring systems (pp. 25-50). New York: Academic Press.

Mayer, R. E. (1982). Memory for algebra story problems. Journal of Educational Psychology, 74, 199-216.

Miller, S. P. \& Hudson, P. J. (2007). Using evidence-based practices to build mathematics competence related to conceptual, procedural, and declarative knowledge. Learning Disabilities Research \& Practice, 22(1), 47-57.

National Council of Teachers of Mathematics (2000). Principles and standards for school mathematics. Reston, VA.

Nesher, P. (1986). Are mathematical understanding and algorithmic performance related? For the Learning of Mathematics, 6(3), 2-9.

Nesher, P., Hershkovitz, S., and Novotna, J. (2003). Situation model, text base and what else? Factors affecting problem solving. Educational Studies in Mathematics 52(2), 151-176.

Norton, S. \& Irvin, J. (2007). A concrete approach to teaching symbolic algebra. Retrieved March 24, 2010 from www.merga.net.au/documents/RP502007.pdf

Ontario Ministry of Education (2005). The Ontario Curriculum: Grades 9 and 10 mathematics. Queen's Printer for Ontario.

Ontario Ministry of Education (2007). The Ontario Curriculum: Grades 11 and 12 mathematics. Queen's Printer for Ontario.

Pegg, J. (2010). Promoting the acquisition of higher order skills and understandings in primary and secondary mathematics. Proceedings from the Australian Council for Educational Research [ACER] Conference (pp. 35-38), 15-17 August 2010, Melbourne.

Posner, M. I., \& McLeod, P. (1982). Information processing models, in search of elementary operations. Annual Review of Psychology, 33, 477-514.

Pycior, H. M. (1984). Internalism, externalism and beyond: 19th century British algebra. Historia Mathematica, 11, $424-441$.

Radatz, H. (1979). Error analysis in mathematics education. Journal for Research in Mathematics Education, 10(3), 163-172.

Rittle-Johnson, B. \& Koedinger, K. R. (2005). Designing knowledge scaffolds to support mathematical problem solving. Cognition and Instruction, 23(3), 313-349.

Saenz, C. (2009). The role of contextual, conceptual and procedural knowledge in activating mathematical competencies (PISA). Educational Studies in Mathematics, 71(2), 123-143.

Schoenfeld, A. H. (1985). Mathematical problem solving. Orlando: Academic Press. 
Schoenfeld, A. H. (1992). Learning to think mathematically: Problem solving, metacognition, and sense making in mathematics. In D. Grouws. (Ed.), Handbook of Research on Mathematics Teaching and Learning. (pp. 334-370). NY: Macmillan Publishing Company.

Schoenfeld, A. (2004). The math wars. Educational policy, 18(1), 253-286.

Sierpinska, A. (2008). Difficulties in Learning Algebra. Retrieved March 01, 2013 from

www.annasierpinska.wkrib.com/pdf/HongYueVanier111108.pdf

Skemp, R. R. (1987). The psychology of learning mathematics. USA: Erlbaum Associates.

Stacey, K. \& Chick, H. (2004). Solving the problem with algebra. In K. Stacey, H. Chick, \& M. Kendal (Eds.), The Future of Teaching and Learning of Algebra. The 12th ICMI Study (pp. 1-20). Boston: Kluwer.

Stacey, K. \& MacGregor, M. (1999). Algebraic sums and products: Students' concepts and symbolism. In J. P. da Ponte \& J. F. Matos (Eds.), Proceedings of the 18th International Conference for the Psychology of Mathematics Education, Vol. 43, Lisbon, Portugal, pp. 289-296.

Swafford, J. O. \& Langrall, C. W. (2000). Grade 6 students' pre-instructional use of equations to describe and represent problem situations. Journal for Research in Mathematics Education, 31(1), 89-112.

Usiskin, Z. (1988). Conceptions of school algebra and uses of variables. In A. F. Coxford \& A. P. Shulte (Eds.), The ideas of algebra, K-12: 1988 yearbook (pp. 8-19). National Council of Teachers of Mathematics.

Van de Walle, J. \& Folk, S. (2008). Elementary and middle school mathematics: Teaching developmentally. Second Canadian Edition, Toronto, ON: Pearson Education Canada.

Wagner, S. \& Parker, S. (1999). Advancing Algebra. In B. Moses (Ed), Algebraic Thinking. Reston, VA. NCTM.

Warren, E. (2003). The role of arithmetic structure in the transition from arithmetic to algebra.

Mathematics Education Research Journal, 15(2), 122-137.

Wheeler, D. (1989). Contexts for research on the teaching and learning of algebra. In S. Wagner \& C. Kieran (Eds.), Research agenda for mathematics education: Vol.4, Research issues in the learning and teaching of algebra (pp. 278-287). NJ:Erlbaum.

Wilson, J. \& Clarke, D. (2004). Towards the modeling of mathematical metacognition. Mathematics Education Research Journal, $16(2), 25-48$.

$\mathrm{Wu}, \mathrm{H}$. (2001). How to prepare students for algebra. American Educator, 25 (summer), 10-17. 